\title{
Effect of Vocational College Students Interested in Reading Professi onal Books in CAI Network
}

\author{
Lang Liao ${ }^{1}$, Zhang Haiping ${ }^{1}$ \\ Shenzhen Institute of Information Technology, ShenZhen GuangDong 518172, China;
}

Keywords:computer assisted instruction; professional books; learning interest

\begin{abstract}
.
In current higher vocational college, the computer aided teaching is widely used, but the stu dents have low interest in reading the professional book. Aimed to this problem, the comput er aided teaching platform is extended to the network, through the forum, micro-blog and email and other means, the students can acquire teaching resources whenever and wherever in possible. The three dimensional interactive teaching model is formed to promote the students' interesting in professional knowledge learning. Through the analysis of the survey of $146 \mathrm{c}$ ollege students, following conclusions can be obtained: the computer aided teaching networkp latform can improve the interest of students in reading professional books, the interesting tea ching courseware with rich content can improve subjective learning interest of students, it ha s good application value in teaching practice. The students accept expansion network teachin g platform have higher interesting in reading professional books than the students accept rea ding paper books.
\end{abstract}

\section{Introduction}

In recent years, with the rapid development of computer and network technology, compute $r$ aided teaching mode is widely applied in higher vocational colleges. Combining the multim edia teaching mode with sound photoelectric and image processing technology, the sensory a cceptance ability of students is stimulated, and the learning interest of the students is improv ed. The teaching efficiency is improved greatly in the past ten years. But at the same time, with the rapid development of science and technology, the higher vocational education is faci ng more opportunities and challenges, more and more students are using intelligent mobile $\mathrm{p}$ hone and other high-tech products for reading books, the reading habits of students is changi ng[1], it puts forward higher requirements for the higher vocational education. The higher vo cational education needs to provide a broad learning platform for students with richer connot ation knowledge and more vivid and colorful teaching methods. The teaching quality and effi ciency can be improved. More space and time are saved for developing the independent oper ations and activities for students. In order to cultivate high-quality talents with modern consc iousness, in this paper the computer aided teaching platform is extended to the network, thro ugh the forum, micro-blog and e-mail and other means, the students can acquire teaching res ources whenever and wherever in possible[2]. The three dimensional interactive teaching mod el is formed to promote the students' interesting in professional knowledge learning. Researc $\mathrm{h}$ results show that this mode has good application value in practice. 


\section{Computer aided teaching and network}

Computer assisted instruction (CAI) is developed in this modern society, its development has made the teaching form and mode changed greatly, in order to improve the teaching qua lity and efficiency, CAI is integrated into the practice of teaching in all subjects through var ious forms of image and sound, CAI uses the open style teaching form, the dynamic electro nic courseware, multimedia tutorials and man-machine interactive exercises and other means a re used in the CAI system, students are defined as the teaching main body status in CAI, th e enthusiasm of the students are mobilized and stimulated. The teaching quality is greatly im proved. CAI overcome the problems of traditional such as teaching method is single, teachin $\mathrm{g}$ content is too stiff, etc. So that students can overcome the limitation of space and time, $t$ heir imagination and creativity are developed fully[3].

Computer aided teaching not only can reduce the unnecessary time, teacher imparting proc ess cost is reduced, and improve teaching efficiency, but also has it has the characteristics o $\mathrm{f}$ vivid expressing forming. The teaching content of computer aided teaching process is more simple and concrete, it can improve the efficiency of the students accept the teaching conte nt, furthermore, the computer aided teaching also pay attention to combine chart and color, $s$ ound and images, dynamic and static. The form is novel with diversity. The current higher $\mathrm{v}$ ocational teaching usually make the teaching content into an electronic courseware, coursewar e content is developed from easy to difficult step by step. Electronic courseware also can en large the text, change the color, the important contents are focused on and emphasized. It ca $\mathrm{n}$ deepen students' memories and impression. Electronic courseware can contain a large numb er of teaching contents, so it is able to span the boundaries of time and space, and the hori zontal comparison is analyzed to strengthen communication and contacts between knowledge of different subjects[5].

The computer aided teaching can fully demonstrate its strong creativity and superiority, wi th the advent of micro-blog, blog and other communication platform, the computer aided tea ching is faced with the problem of upgrading technology, platform extension etc.. In recent years, the number of vocational college students increased rapidly, the growing learning spac e requirements of students has contradictions to the existing education resources, our schools need to build more broad learning platform for students, and make more interesting course ware to meet the needs of students in Higher Vocational colleges.

According to the computer aided teaching based on network teaching platform, the comput er assisted instruction is extended to the high-speed network, including network multimedia c ourseware system, multimedia classroom system network and the network distance education system. Existing multimedia classroom and teaching resources are limited in current vocationa l colleges, the network assisted teaching system platform should be constructed, it can enable students to acquire resources for learning professional whenever and wherever in possible th rough the network, also it can provide students with more flexible learning mode. The CAI teaching based on network teaching platform can enable students to use network access to th e latest knowledge, and the students can use the computer, intelligent mobile phone and othe $r$ equipment to download the latest software and professional knowledge in multimedia cours eware system. The students can avoid in searching for a needle in a haystack like for collec ting available data. So the new mode saves a large amount of data collection time for stude nts. CAI teaching system based on network teaching platform not only can provide more res 
ources for students, but also allows teachers to publish short learning resources by micro-blo $\mathrm{g}$ and forums. Through the email system of class, interaction with students is obtained. Stud ents use the email and forum and teachers to communicate and solve the problems in study. All kinds of resources of network provided by the teaching platform can create a similar re al environment, promoting active exploration in the knowledge of students. The active learnin $\mathrm{g}$ and constructivism are completed.

\section{Model research of Network CAI aided reading teaching}

In this research, 150 questionnaire copies are developed. 2011 grade students are taken as the study objects, the multimedia classrooms are constructed, the effective questionnaire are 146 copies. Correlation analysis is applied in analysis of influence of auxiliary teaching of computer network to improve the professional books reading interest.

\section{A.Research assumption}

The rapid development of today's network, it provides a good platform for the dissemination of knowledge. But the excess data and scattered storage space increase the time and the difficulty for acquisition of appropriate data. Network computer-assisted teaching system can make the students more convenient access to learning resources, and it enables students to save the collection and screening time of the books, the interests are increased, so as to enable students to have more time for reading and studying. More books and information can be obtained in the information network platform, and the attraction for students is more. The students have higher interest in reading professional books. We propose assumption 1.

Assumption 1: On the network platform, the number of books and resources students can be obtained has positive correlation with the enhance interest of students reading professional books.

More and more researches think that computer aided teaching can improve the students' interest in learning professional books, network teaching platform provides professional books covers more knowledge, it can provide more help for students interested in ascension, the profound and more practical theories in simple language can stimulate students' interest in reading. The assumption 2 it proposed.

Assumption 2: The quality of professional books and students' interest in reading on the teaching network platform has positive correlation.

The computer aided teaching based on network teaching platform in Higher Vocational Colleges needs to build multiple system platforms on the campus network, such as multimedia courseware system, multimedia classroom system, network distance learning system, etc. Network teaching platform access speed is faster, it more can stimulate the students' desire of browsing, content classification is more detailed, and it is more can cultivate students' reading habits. Thus, assumption 3 is proposed.

Assumption 3: Design level of network teaching platform and interest enhancement of students' reading professional books has positive correlation.

\section{B.Set of variables}

a.Students interest variables of reading professional books 
In this survey, the surveyed students is limited in the specified range of professional books, including professional foundation course books, professional skills and professional original books. The students' subjective professional books reading interest (SIT) is taken as the dependent variable, the authenticity of results is enhanced and ensured.

b.Parameters of network computer aided teaching platform

The parameters variables of network computer aided teaching platform are defined as the network source number, the speed of network access, network platform data classification and reading difficulty. The data availability are taken as regression variables

c.Control variables

In this paper, the students characteristic variables are selected as the control variables, where S1 denotes the students' gender, S2 is shown as students grade.

\section{B.Construction of research model}

In this paper, EViews7.0 software is used for analyzing the relationship between networked computer aided teaching and improvement of students' interest in reading professional books. In this paper, multivariate linear models are taken for the quantitative analysis of the relationship, and the hypothesis testing are taken for the mathematical processing, the model is shown as:

$$
\operatorname{SIT}_{\mathrm{i}}=\alpha_{\mathrm{i}}+\beta_{\mathrm{i}} \mathrm{CAIS}_{\mathrm{i}}+\gamma_{1} \mathrm{~S}_{1}+\gamma_{2} \mathrm{~S}_{2}+\varepsilon_{\mathrm{i}}
$$

In this formula, $\alpha_{\mathrm{i}}$ is the constant item, $\beta_{\mathrm{i}}$ and $\gamma_{\mathrm{i}}$ are regression parameters, $\varepsilon \mathrm{i}$ is the random disturbance term.

\section{Networked CAI teaching effect on the students' interest in reading}

\section{A.Analysis of descriptive statistics}

The parameters setting results are expressed in Table 1.

\begin{tabular}{|c|c|c|c|c|}
\hline \multicolumn{5}{|c|}{ Table 1 Descriptive statistics } \\
& & & & Std. \\
& Min & Max & Mean & Deviation \\
\hline SIT & 1.19 & 4.06 & 2.0000 & 10.45727 \\
CAIS $_{1}$ & 1.05 & 5.6424 & 3.107324 & 15.03382 \\
CAIS $_{2}$ & 1.05 & 5.6424 & 3.107324 & 15.03382 \\
CAIS $_{3}$ & 1.05 & 5.6424 & 3.107324 & 15.03382 \\
S $_{1}$ & 0.0834 & 0.8216 & 0.349823 & 13.99959 \\
S $_{2}$ & 0.50 & 2.00 & 1.500000 & 14.53247 \\
\hline
\end{tabular}

146 questionnaires data are taken with descriptive statistical analysis, and the results are shown in Table 1. The sample descriptive statistics results are obtained. We can get the conclusions as 
following: first, the enhancement fluctuation of the ability of students in the school is big, and the gap between students reading ability is obvious. Second, the learning time of students use the multimedia classroom is more than the single machine learning, network teaching platform is facilitate to the students' spare time training reading ability. Third, although students come from the same school, but obviously numbers of girls are more than boys. And girls learning time averaged is more than boys, the test of students are more than boys. On the other side, girls average effort than boys. Fourth, students are come from four different classes, the teachers from lecturer to Professor in difference. The teacher's office level has an effect on the ability of students.

\section{C.Networked computer aided teaching and correlation test of students' interest in reading}

In this paper, the multiple linear regression method is used to test the relationship between the model and the interest enhancement. According to the analysis as above, the results of multiple linear regression estimation are expressed in Table 2.

Table 2 Results of multiple linear regression estimation

Dependent Variable: SIT

Method: Multivariable Linear Regression Model

Date: 10/02/12 Time: 21:27

Sample: 1146

Included observations: 146

Convergence achieved after 4 iterations

Covariance matrix computed using second derivatives

\begin{tabular}{|c|c|c|c|c|}
\hline Variable & Coefficient & Std. Error & z-Statistic & Prob. \\
\hline a & 12.624711 & 20.873959 & 1.838700 & $\overline{0.000000}$ \\
\hline CAIS $_{1}$ & 4.743978 & 2.368520 & 2.002929 & 0.045185 \\
\hline $\mathrm{CAIS}_{2}$ & 2.661123 & 2.567735 & 1.036370 & 0.050030 \\
\hline $\mathrm{CAIS}_{3}$ & 3.641078 & 2.520488 & 1.444593 & 0.048572 \\
\hline $\mathrm{S}_{1}$ & 2.478035 & 2.585062 & 0.958598 & 0.067761 \\
\hline $\mathrm{S}_{2}$ & 3.691586 & 0.566861 & 6.512329 & 0.000000 \\
\hline \multicolumn{2}{|c|}{ Mean dependent var } & 33.045977 S.D.dependent var & & 26.151130 \\
\hline \multicolumn{2}{|c|}{ S.E. of regression } & 11.640598 Akaike info criterion & & 7.968462 \\
\hline \multicolumn{2}{|c|}{ Sum squared resid } & 27.260938 Schwarz criterion & & 8.365275 \\
\hline \multicolumn{2}{|c|}{ Log likelihood } & 22.628103Hannan Quinn criter. & & 8.128246 \\
\hline \multicolumn{2}{|c|}{ Avg. log likelihood } & -3.823312 & & \\
\hline
\end{tabular}

By analyzing the table 2, we can get a preliminary conclusion: The number of computer assisted available instruction on platform is more, students has higher interest in reading professional books, and there is statistically significant positive correlation between the two items. So we get that the assumption 1 is real. The reason is that the computer aided reading teaching based on network platform can temporarily alleviate the students for the professional books demand. Because the school resource constraints, the students cannot get enough professional books, students can get the books part of the chapter through the Internet platform, it enables students to read these books in 
their spare time. Through the interaction between teachers and students with micro-blog and e-mail, the limit of time and space are broken through, so that the students' reading interest is significantly improved.

Through multiple linear regression estimation, the results show that the CAIS2 coefficient is 2.66, the network teaching platform provides enough books, and it can stimulate students' interest in reading. This mode can enable students to spend more time and energy to read professional books. So the assumption 2 is ensured, at the same time, students have more convenient access to books, it provides more help for students and teachers. The micro-blog and emails of teachers can form the interactive network between students and teachers. The teachers can break through the limit of time and space to guide the students, so the quantity and quality of the students' reading professional books are greatly improved.

\section{Conclusions}

The computer has been applied in various fields, and the computer aided teaching has become an indispensable auxiliary teaching mode of education in the new century, it becomes the needs of social education development. Application and development of computer assisted instruction injects new vitality to the development of Higher Vocational Education in 21C. When higher vocational colleges use computer assisted teaching, we should think about the improvement of the computer aided teaching deeply, the computer assisted instruction platform based on network should catch up with the pace of the information age, and various colleges spend large amounts of time and money making electronic courseware. The education itself should be studied to meet the requirements of the information era. It can break through the limits of time and space for students, and it can provide a broader and more convenient learning platform. Research results show that the computer aided teaching network platform can improve the interest of students in reading professional books, the interesting teaching courseware with rich content can improve subjective learning interest of students, it has good application value in teaching practice.

\section{Acknowledgement}

Higher vocational education information technology project of guangdong province "skills competition with conventional teaching accommodation collaborative innovation practice of reform of teaching mode, project number: XXJS - 2013-1052

\section{References}

[1] Li T, Gopalakrishnan P, Garg R, Shahnam Mehrdad. CFD-DEM study of effect of bed t hickness for bubbling fluidized beds[J].Particuology, 2012, 10(5): 532-541.

[2] Han Mengjie, Zhang Dexiang. On Market Mechanism of Structural Changes in American Higher Education[J].Educational research, 2014,1:124-131.

[3] Xing Jiliang. Research on Method of Fault Information Filtering and Effective Word Fre quency Estimation for Web[J]. Bulletin of Science and Technology, 2014,30(2): 59-61.

[4] CAO Jian, LI Hai- sheng, CAI Qiang. Research on Feature Extraction of Image Target [J]. Computer Simulation, 2013, 30(1): 409-413. 
[5] MO Shao-qiang, LIU Jiang-lin. Design of Logistics Information Collection System Based on Diagram Identification Technology[J]. Logistics Technology, 2012, 31(9): 400-401, 4 16. 